\title{
Effect of retinoic acid-induced transglutaminase on cell growth in regenerat- ing liver
}

\author{
Yosuke Ohtake $^{1}$, Akiko Maruko ${ }^{1}$, Shinya Abe $^{1}$, Manabu Fukumoto ${ }^{2}$, and Yasuhito Ohкubo ${ }^{1}$ \\ ${ }^{1}$ Department of Radiopharmacy, Tohoku Pharmaceutical University, 4-4-1, Komatsushima, Aoba-ku, Sendai, Miyagi 981-8558, Japan, \\ and ${ }^{2}$ Department of Pathology, Institute of Development, Aging and Cancer, Tohoku University, 4-1, Seiryo-machi, Aoba-ku, Sendai, \\ Miyagi 980-8575, Japan
}

(Received 2 February 2006; and accepted 16 February 2006)

\begin{abstract}
Transglutaminase 2 (TG2) is implicated in the inhibitory regulation of the hepatocyte growth in vitro. In vivo, however, the role of TG2 in liver regeneration after partial hepatectomy $(\mathrm{PH})$ is almost unknown. A dramatic increase of TG2 expression and activation is induced by retinoic acid (RA). Here we show the effect of the RA-induced overexpression of TG2 on liver regeneration after $\mathrm{PH}$. Regenerating rat liver was prepared by $70 \% \mathrm{PH}$. RA was intraperitoneally injected immediately after $\mathrm{PH}$. TG2 activity was determined by incorporation of ${ }^{14} \mathrm{C}$-putrescine into dimethylcasein. Cell cycle was evaluated for incorporation of BrdU into hepatocytes and detected by a flow cytometric analysis. The treatment of RA greatly increased TG2 activity at 1 day after $\mathrm{PH}$. At that time, DNA synthesis was significantly reduced by the treatment of RA. The recovery of liver weight after PH was significantly delayed by the treatment of RA. These results suggested that TG2 was involved in growth capacity in regenerating rat liver after PH.
\end{abstract}

Liver regeneration following $70 \%$ partial hepatectomy $(\mathrm{PH})$ leads to rapid restoration and gains its lost mass within a week after surgery. Liver regeneration is regulated by several factors, including cytokines (9), growth factors (20), and post-translational modifications of several proteins $(4,6)$. Transglutaminase 2 (TG2; EC 2.3.2.13) catalyzes $\mathrm{Ca}^{2+}$-dependent posttranslational modification of proteins $(10,31$, $32,34)$. The role of TG2 in liver regeneration after $\mathrm{PH}$ is yet unknown, nor is the mechanism regulating cell growth completely understood. TG2 has been reported to be a negative regulator to cell growth, for example, the induction of a shift from the proliferative to non-proliferative state by an increase in TG2-catalyzed isopeptide bonds in cells (2) or by

Address correspondence to: Dr. Yosuke Ohtake 4-4-1, Komatsushima, Aoba-ku, Sendai, Miyagi 981-8558, Japan

Tel: +81-22-727-0121, Fax: +81-22-275-2013

E-mail: y-ohtake@tohoku-pharm.ac.jp induction of TG2-induced apoptosis $(8,17)$. We have reported that inhibition of de novo synthesis of TG2 resulted in an increased growth of normal rat hepatocytes in the presence of epidermal growth factor (EGF) (15) or hepatocyte growth factor (HGF) (16). Taking these studies into consideration, it is possible that TG2 may be at least partially involved in suppression of hepatocyte growth during liver regeneration. To test this possibility, we investigated the effect of the stimulated expression of TG2 on hepatocyte proliferation after $\mathrm{PH}$.

Retinoic acid (RA), a metabolic derivative of vitamin A, plays a crucial role in many biological functions, such as proliferation, differentiation and fetal development $(13,24)$. RA is an inducer of TG2 expression $(29,30)$, and the mechanism by which RA up-regulates TG2 expression has been elucidated. RA binds to RA receptors and stimulates their association with specific DNA motifs located in the promoter region of the TG2 gene, resulting in transcriptional activation of TG2 (21). 
In the present study, we examined the effect of stimulated expression of TG2 activity by RA treatment on hepatocyte proliferation in regenerating rat liver after $\mathrm{PH}$.

\section{MATERIALS AND METHODS}

Materials. $\left[1,4-{ }^{14} \mathrm{C}\right]$ putrescine dihydrochloride was purchased from PerkinElmer Life Sciences, Inc. (Boston, MA). Collagenase was from Nitta Gelatin (Osaka, Japan). Retinoic acid (RA) and bromodeoxyuridine (BrdU) were from Sigma-Aldrich (St. Louis, MO). All other reagents were purchased from Nakarai Tesque (Tokyo, Japan).

Animals. Male Wistar rats weighing 200-230 g (SLC, Hamamatsu, Japan) were kept at a controlled temperature $\left(23 \pm 1^{\circ} \mathrm{C}\right)$ under a $12 \mathrm{~h}$ light-dark cycle and were maintained with a standard diet and water. All animal experiments were performed in strict accordance with the institutional animal committee's criteria for the care and use of laboratory animals.

Partial hepatectomy $(P H)$. Seventy \% of PH was performed under light ether anesthesia according to the method of Higgins and Anderson (11). Rats were sacrificed at $0,1,2$, and 3 days after surgery.

$R A$ treatment. RA ( $15 \mathrm{mg} / \mathrm{kg}$ body weight), dissolved in corn oil/dimethylsulfoxide $(1: 1)$, was intraperitoneally injected immediately after $\mathrm{PH}$. Control rats received the same quantity of the vehicle as the experimental animals.

Isolation of hepatocytes from partially hepatectomized rat liver. Hepatocytes were obtained from livers of normal and partially hepatectomized rats. Hepatocytes were isolated by the collagenase perfusion method (33) with a minor modification (16) and obtained by centrifugation $(2 \mathrm{~min}$ at $50 \times \mathrm{g}$ ).

Determination of DNA synthesis. The cell cycle was analyzed using BrdU Flow Kit (Becton Dickinson, San Diego, CA). BrdU was dissolved in phosphate buffered saline (PBS) and was given intravenously $(10 \mathrm{mg} / \mathrm{kg}$ body weight) $2 \mathrm{~h}$ before killing. BrdU incorporation (detected with FITC-conjugated anti-Br$\mathrm{dU}$ monoclonal antibody) and total DNA content (detected with 7-amino-actinomycin D (7-AAD)) in hepatocytes were monitored by FACScan (Becton Dickinson).

Measurement of TG2 activity. After the digitonin/ collagenase perfusion, the cell suspension was homogenized with 9 volumes of ice-cold buffer $(0.25 \mathrm{M}$ sucrose, $10 \mathrm{mM}$ Tris, $2 \mathrm{mM}$ EGTA, $2 \mathrm{mM} \mathrm{MgCl}_{2}$, $1 \mathrm{mM}$ phenylmethylsulfonylfluoride, $\mathrm{pH}$ 7.4) by 15 strokes using a loose-fitting Dounce homogenizer. The homogenate was centrifuged at $105,000 \times g$ for $60 \mathrm{~min}$ at $4^{\circ} \mathrm{C}$. Aliquots of the resultant supernatant were used as the cytosol fraction for the TG2 assay. TG2 activity of the cytosolic fraction was assayed by incorporation of $\left[1,4-{ }^{14} \mathrm{C}\right]$ putrescine into $N, N^{\prime}$-dimethylcasein as described previously (15). The reaction mixture contained $50 \mathrm{mM}$ Tris- $\mathrm{HCl}$ (pH 7.4), $10 \mathrm{mM}$ dithiothreitol, $5 \mathrm{mM} \mathrm{CaCl} 2,0.5 \mathrm{mg}$ of $N, N^{\prime}$-dimethylcasein, and $1 \mathrm{mM}$ putrescine including $1.85 \mathrm{kBq}$ of radioactive putrescine. Reaction was initiated by addition of each sample solution $(20 \mu \mathrm{L})$ followed by incubation at $37^{\circ} \mathrm{C}$ in a total volume of $50 \mu \mathrm{L}$. After $5 \mathrm{~min}$ incubation, the reaction was stopped by spotting $40 \mu \mathrm{L}$ onto Whatman $3 \mathrm{MM}$ filter paper, which was then immersed in $10 \%$ trichloroacetic acid solution. The radioactivity of each filter paper was measured by liquid scintillation counting. The enzyme activity was expressed as nmol putrescine incorporated into dimethylcasein/ $\mathrm{min} / \mathrm{mg}$ protein of sample. Protein concentration was determined according to the method of Bradford (3) using bovine serum albumin as a standard.

Statistical analysis. Statistical analysis was performed by the Mann-Whitney test.

\section{RESULTS}

The effect of RA on induction of TG2 activity after $\mathrm{PH}$

We measured changes in TG2 activities in hepatocytes from RA-treated or -untreated rat liver after PH (Fig. 1). In RA-treated rat, TG2 activity significantly increased at 1 day after $\mathrm{PH}$, and reached a maximum, 3-times of that from RA-untreated rat, whereas in RA-untreated rat, its activities at 1 to 3 days after PH were almost the same as initial level.

\section{The effect of RA on DNA synthesis after PH}

To see the effect of RA on DNA synthesis during liver regeneration, BrdU incorporation and total DNA content in hepatocytes were monitored by flow cytometric analyses (Fig. 2). The relative changes in the amount of DNA synthesis were calculated and plotted as percentages of FITC signals against 7-AAD signals (Fig. 3). In RA-untreated rat, DNA synthesis increased transiently with a peak at 1 day after PH, whereas in RA-treated rat, the peak 
of DNA synthesis shifted to 2 days after $\mathrm{PH}$ and the peaked amount of DNA synthesis was almost the same as that in RA-untreated rat at 1 day after $\mathrm{PH}$.

The effect of $R A$ on liver weight after $\mathrm{PH}$

Surgical resection of $70 \%$ of the liver led to a twofold increase of the weight of the remaining hepatic lobes 3 days after PH in RA-untreated rats. However, the recovery of liver weight was significantly delayed by RA treatment at a dose of $15 \mathrm{mg} / \mathrm{kg}$ body weight (Fig. 4).

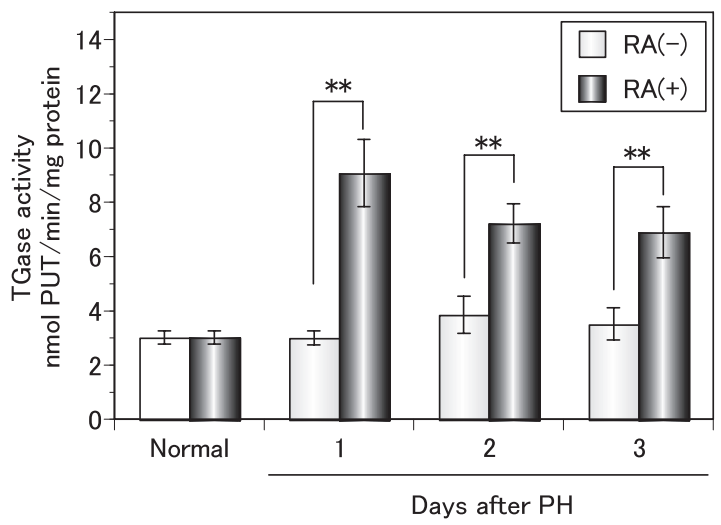

Fig. 1 Time courses of TG2 activity in partially hepatectomized rat liver treated with or without RA. Each value represents the mean \pm SEM of $4-6$ rats. ${ }^{* *} p<0.01$, RA untreated rats vs. RA treated rats.

\section{DISCUSSION}

TG2 catalyzes a calcium-dependent transamidation reaction which results in cross-linking of proteins through the formation of $\varepsilon$-( $\gamma$-glutamyl) lysine ( 7 , $22)$. The biological activity of TG2 has been implicated in extracellular matrix organization (1), activation of cytokines and growth factors such as transforming growth factor- $\beta$ (19) and midkine (18). As shown in Fig. 1, when RA was injected immediately after PH, TG2 level was significantly induced. However, it is not certain whether RA-induced TG2 indicates the biological activity. The measurement of TG2 activity in vitro assay indicates the amount of TG2 protein because of the treatment of calcium which results in complete activation of TG2. At this point, it is reported that RA has been shown to augment the expression of TG2 mRNA levels (5), and Piacentini et al. also observed an increase of TG2 activity in RA-treated rat liver (30). Therefore, we think that TG2 activity assayed in the present study accurately reflects the biological activity.

Shortly after PH, the EGF plasma level is elevated two to threefold (27). Thus, activation of EGF receptor is likely to be involved in G1 phase progression during liver regenerative growth. We previously reported that TG2 negatively regulated the growth signal of EGF through down-regulating their receptors (14). HGF is also known as a potent mito-
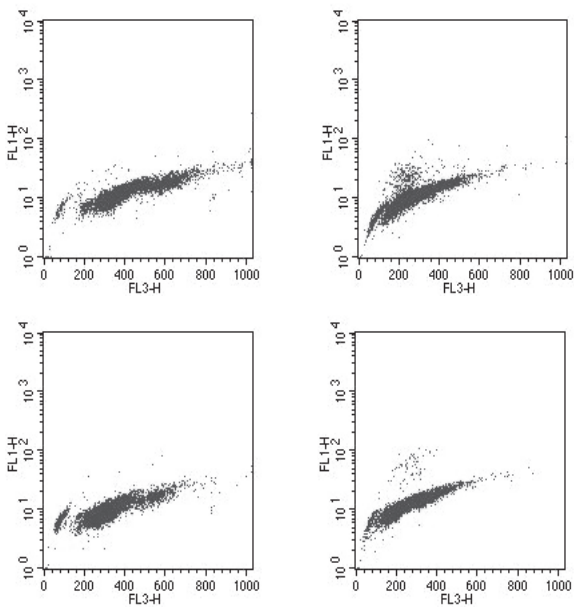

Normal
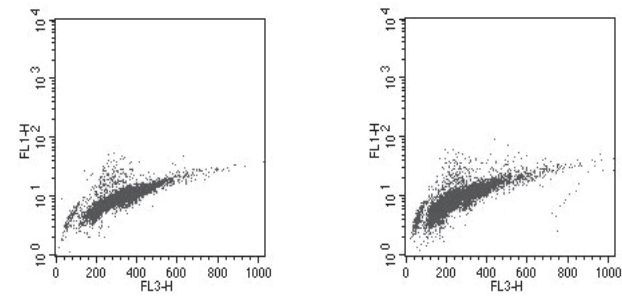

RA (-)

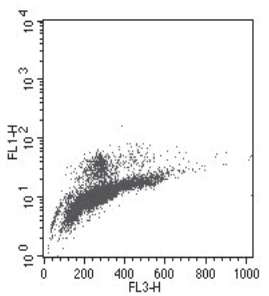

2 day

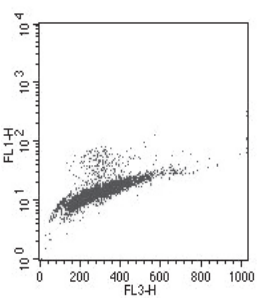

3 day

\section{After $\mathrm{PH}$}

Fig. 2 Flow cytometric analyses of the cell cycle in partially hepatectomized rat liver treated with or without RA. These data are representative ones of 4-6 experiments with similar results. 


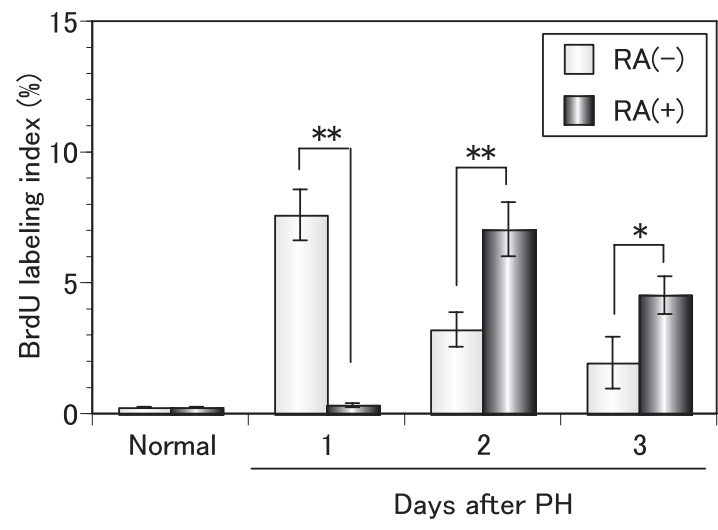

Fig. 3 Time courses of DNA synthesis in partially hepatectomized rat liver treated with or without RA. Each value represents the mean \pm SEM of $4-6$ rats. ${ }^{*} p<0.05$, ${ }^{* *} p<0.01$, RA untreated rats vs. RA treated rats.

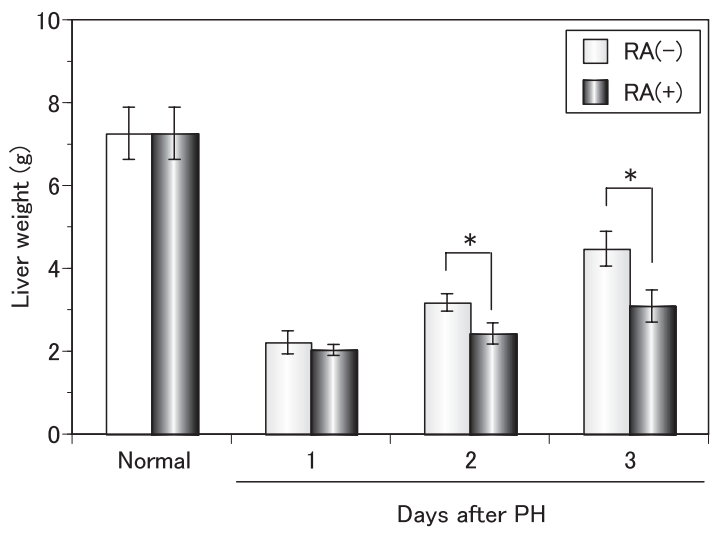

Fig. 4 The effect of RA on liver weight after partial hepatectomy. RA (15 mg/kg body weight) was intraperitoneally injected immediately after partial hepatectomy. Each value represents the mean \pm SEM of $4-6$ rats. ${ }^{*} p<0.05$, RA untreated rats vs. RA treated rats.

Growth stimulation by partial hepatectomy

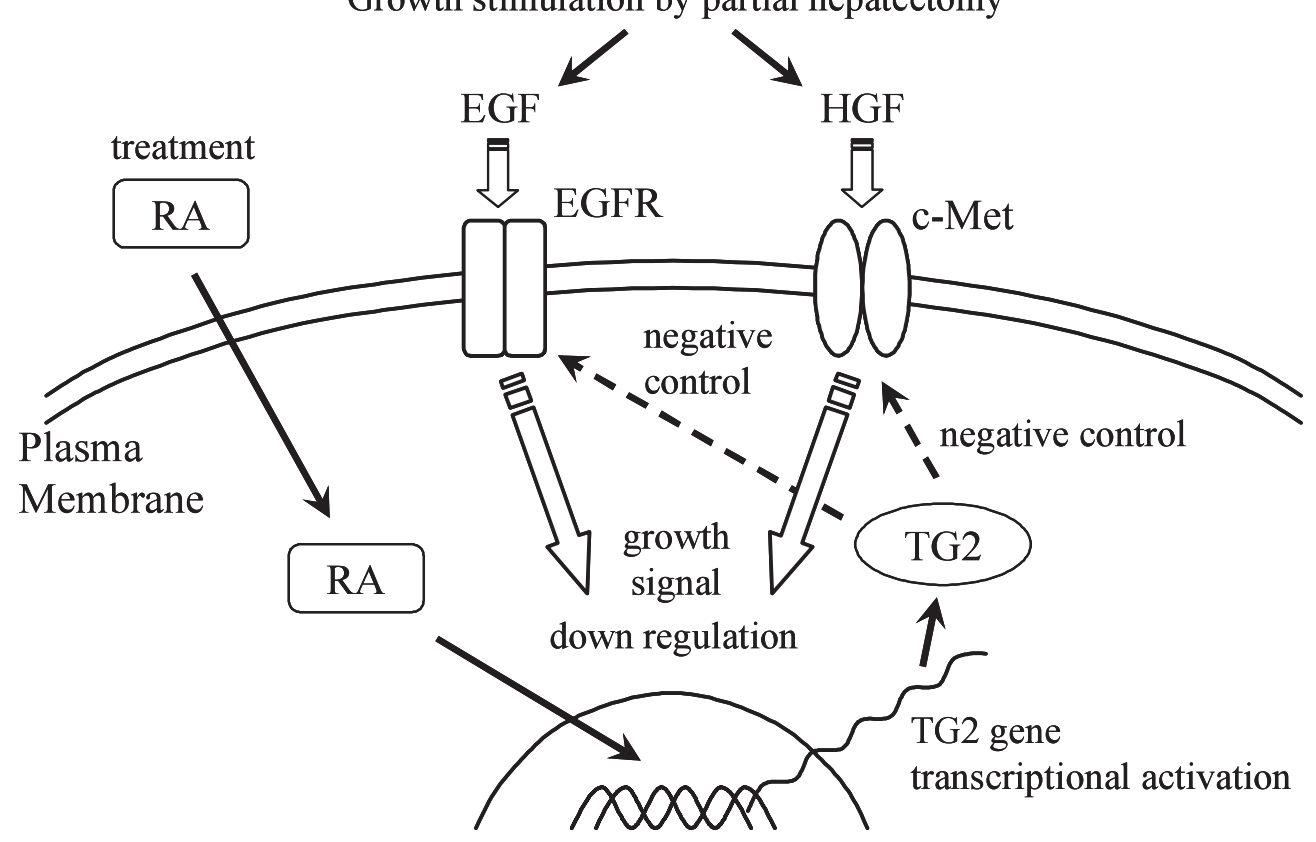

\section{Nucleus}

Fig. 5 A schematic illustration of the negative regulation of cell growth by RA-induced TG2 through the down regulation of growth factor receptor such as EGF and HGF

gen for mature hepatocytes and acts as an important factor on regenerating rat liver $(23,26)$. We found that HGF-induced TG2 activity in hepatocytes and its inhibition resulted in stimulation of hepatocyte growth and that this stimulatory effect resulted from the inhibition of down regulation of c-Met, a receptor for HGF (16). These findings suggest that hepatocyte growth was negatively regulated by TG2. Hu et al. reported that the level of EGF receptor in the vitamin A-supplemented animals was down-regulated following $\mathrm{PH}$ (12). Taking the previous results into consideration, the present data suggest that RAinduced higher TG2 expression at 1 day after $\mathrm{PH}$ may lead to down regulation of growth factor receptor (see a schematic illustration, Fig. 5), resulting that the peak of DNA synthesis shifts from 1- to 
2-days (Fig. 3). As a result, the recovery of liver weight was significantly delayed by the treatment of RA (Fig. 4). The weight of remaining hepatic lobes in RA-treated rats was recovered to original mass after 2 weeks, as well as RA-treated rats (data not shown). These findings suggest that TG2 is related to the cell proliferation at early stages of liver regeneration after $\mathrm{PH}$.

It has been reported that intracellular TG2 may be involved in the suppression of cell growth. Piacentini et al. reported that the induction of TG2 and the formation of TG2-catalyzed isopeptide bonds were directly correlated with the formation of apoptotic bodies (28). Melino et al. demonstrated that the overexpression of TG2 resulted in a drastic reduction in the proliferative capacity of human neuroblastoma cells by apoptosis (25). Taking the previous reports into consideration, it is possible that TG2 affects the cell growth through the crosslinking of different TGase substrates in different cell state, resulting in the induction of apoptosis or down regulation of growth factor receptor.

We expect that TG2 is one of many factors which are involved in the regulation of hepatocyte proliferation during liver regeneration after PH. Further detailed studies are necessary to elucidate the role of intracellular TG2 on liver regeneration.

\section{REFERENCES}

1. Aeschlimann D and Paulsson M (1994) Transglutaminases: protein cross-linking enzymes in tissues and body fluids. Thromb Haemost 71, 402-415.

2. Birckbichler PJ, Orr GR, Patterson MK, Jr., Conway E and Carter HA (1981) Increase in proliferative markers after inhibition of transglutaminase. Proc Natl Acad Sci USA 78, 5005-5008.

3. Bradford MM (1976) A rapid and sensitive method for the quantitation of microgram quantities of protein utilizing the principle of protein-dye binding. Anal Biochem 72, 248-254.

4. Caraglia M, Vitale G, Marra M, Del Prete S, Lentini A, Budillon A, Beninati S and Abbruzzese A (2004) Translational and post-translational modifications of proteins as a new mechanism of action of alpha-interferon: review article. Amino Acids 26, 409-417.

5. Chiocca EA, Davies PJ and Stein JP (1988) The molecular basis of retinoic acid action. Transcriptional regulation of tissue transglutaminase gene expression in macrophages. $J$ Biol Chem 263, 11584-11589.

6. Esposito C and Caputo I (2005) Mammalian transglutaminases. Identification of substrates as a key to physiological function and physiopathological relevance. Febs $J$ 272, 615631.

7. Fesus L and Piacentini M (2002) Transglutaminase 2: an enigmatic enzyme with diverse functions. Trends Biochem Sci 27, 534-539.

8. Fesus L, Thomazy V and Falus A (1987) Induction and activation of tissue transglutaminase during programmed cell death. FEBS Lett 224, 104-108.

9. Galun E and Axelrod JH (2002) The role of cytokines in liver failure and regeneration: potential new molecular therapies. Biochim Biophys Acta 1592, 345-358.

10. Heath DJ, Downes S, Verderio E and Griffin M (2001) Characterization of tissue transglutaminase in human osteoblastlike cells. J Bone Miner Res 16, 1477-1485.

11. Higgins GM and Anderson RM (1931) Experimental pathology of the liver. I. Restration of the liver of the white rat following partial surgical removal. Arch Pathol 12, 186-202.

12. $\mathrm{Hu}$ Z, Fujio K, Marsden ER, Thorgeirsson SS and Evarts RP (1994) Hepatic regeneration in vitamin A-deficient rats: changes in the expression of transforming growth factor alpha/epidermal growth factor receptor and retinoic acid receptors alpha and beta. Cell Growth Differ 5, 503-508.

13. Kastner P, Mark M and Chambon P (1995) Nonsteroid nuclear receptors: what are genetic studies telling us about their role in real life? Cell 83, 859-869.

14. Katoh S, Hashimoto M, Kohno H and Ohkubo Y (1993) Calcium pretreatment induces the decrease in epidermal growth factor binding through the activation of transglutaminase in isolated liver membrane. Arch Biochem Biophys 303, 421428.

15. Katoh S, Nakagawa N, Yano Y, Satoh K, Kohno H and Ohkubo Y (1996) Transglutaminase induced by epidermal growth factor negatively regulates the growth signal in primary cultured hepatocytes. Biochem J 313, 305-309.

16. Katoh S, Nakagawa N, Yano Y, Satoh K, Kohno H, Ohkubo Y, Suzuki T and Kitani K (1996) Hepatocyte growth factor induces transglutaminase activity that negatively regulates the growth signal in primary cultured hepatocytes. Exp Cell Res 222, 255-261.

17. Knight CR, Rees RC and Griffin M (1991) Apoptosis: a potential role for cytosolic transglutaminase and its importance in tumour progression. Biochim Biophys Acta 1096, 312-318.

18. Kojima S, Inui T, Muramatsu H, Suzuki Y, Kadomatsu K, Yoshizawa M, Hirose S, Kimura T, Sakakibara S and Muramatsu T (1997) Dimerization of midkine by tissue transglutaminase and its functional implication. J Biol Chem 272, 9410-9416.

19. Kojima S, Nara K and Rifkin DB (1993) Requirement for transglutaminase in the activation of latent transforming growth factor-beta in bovine endothelial cells. J Cell Biol 121, 439-448.

20. Koniaris LG, McKillop IH, Schwartz SI and Zimmers TA (2003) Liver regeneration. J Am Coll Surg 197, 634-659.

21. Lesort M, Tucholski J, Miller ML and Johnson GV (2000) Tissue transglutaminase: a possible role in neurodegenerative diseases. Prog Neurobiol 61, 439-463.

22. Lorand L and Graham RM (2003) Transglutaminases: crosslinking enzymes with pleiotropic functions. Nat Rev Mol Cell Biol 4, 140-156.

23. Matsumoto K and Nakamura T (1992) Hepatocyte growth factor: molecular structure, roles in liver regeneration, and other biological functions. Crit Rev Oncog 3, 27-54.

24. Means AL and Gudas LJ (1995) The roles of retinoids in vertebrate development. Annu Rev Biochem 64, 201-233.

25. Melino G, Annicchiarico-Petruzzelli M, Piredda L, Candi E, Gentile V, Davies PJ and Piacentini M (1994) Tissue transglutaminase and apoptosis: sense and antisense transfection studies with human neuroblastoma cells. Mol Cell Biol 14, 6584-6596.

26. Michalopoulos GK and Zarnegav R (1992) Hepatocyte growth factor. Hepatology 15, 149-155. 
27. Noguchi S, Ohba Y and Oka T (1991) Influence of epidermal growth factor on liver regeneration after partial hepatectomy in mice. $J$ Endocrinol 128, 425-431.

28. Piacentini M, Autuori F, Dini L, Farrace MG, Ghibelli L, Piredda L and Fesus L (1991) "Tissue" transglutaminase is specifically expressed in neonatal rat liver cells undergoing apoptosis upon epidermal growth factor-stimulation. Cell Tissue Res 263, 227-235.

29. Piacentini M, Ceru MP, Dini L, Di Rao M, Piredda L, Thomazy V, Davies PJ and Fesus L (1992) In vivo and in vitro induction of 'tissue' transglutaminase in rat hepatocytes by retinoic acid. Biochim Biophys Acta 1135, 171-179.

30. Piacentini M, Fesus L, Sartori C and Ceru MP (1988) Retinoic acid-induced modulation of rat liver transglutaminase and total polyamines in vivo. Biochem $J$ 253, 33-38.
31. Sato N, Ohtake Y, Kato H, Abe S, Kohno H and Ohkubo Y (2003) Effects of polyamines on histone polymerization. $J$ Protein Chem 22, 303-307.

32. Sato N, Ohtake Y, Kohno H, Abe S and Ohkubo Y (2003) Inhibitory and promotive effects of polyamines on transglutaminase-induced protein polymerization. Protein Pept Lett 10, 396-403.

33. Seglen PO (1976) Preparation of isolated rat liver cells. Methods Cell Biol 13, 29-83.

34. Verderio E, Coombes A, Jones RA, Li X, Heath D, Downes $S$ and Griffin M (2001) Role of the cross-linking enzyme tissue transglutaminase in the biological recognition of synthetic biodegradable polymers. J Biomed Mater Res 54, 294 304. 